\title{
Using a Conflict Framework Analysis to Help Beekeepers and Giant Armadillos (Priodontes maximus) Coexist
}

\author{
Mariana L. Catapani ${ }^{*}$, Carla Morsello ${ }^{1,2+}$, Bruna Oliveira ${ }^{3}$ and Arnaud L. J. Desbiez ${ }^{3,4,5+}$ \\ ${ }^{1}$ Post-Graduate Program in Environmental Science, Institute of Energy and Environment, University of São Paulo, São Paulo, \\ Brazil, ${ }^{2}$ Escola de Artes, Ciências e Humanidades, Universidade de São Paulo, São Paulo, Brazil, ${ }^{3}$ Instituto de Conservação \\ de Animais Silvestres (ICAS), Campo Grande, Brazil, ${ }^{4}$ Royal Zoological Society of Scotland (RZSS), Murrayfield, Edinburgh, \\ United Kingdom, ${ }^{5}$ Instituto de Pesquisas Ecológicas (IPE), São Paulo, Brazil
}

OPEN ACCESS

Edited by: Silvio Marchini, University of São Paulo, Brazil

Reviewed by: Jeremy Cusack, Major University, Chile Jennifer Bond,

Charles Sturt University, Australia

*Correspondence:

Mariana L. Catapani macatapani@hotmail.com

†These authors share last authorship

Specialty section:

This article was submitted to Human-Wildlife Dynamics, a section of the journal Frontiers in Conservation Science

Received: 16 April 2021

Accepted: 29 July 2021 Published: 21 September 2021

Citation:

Catapani ML, Morsello C, Oliveira B and Desbiez ALJ (2021) Using a Conflict Framework Analysis to Help Beekeepers and Giant Armadillos (Priodontes maximus) Coexist.

Front. Conserv. Sci. 2:696435. doi: 10.3389/fcosc.2021.696435
Damage caused by wildlife is one reason preventing peaceful coexistence between humans and wildlife. To identify the complexity and scope of human-wildlife interactions and to guide conservation interventions, a theoretical framework has been recently proposed, based on the field of conflict analysis and peacebuilding. Despite its importance, to our knowledge, there are no studies yet testing the framework. We therefore adapted and expanded the framework to investigate a wildlife-people interaction scenario, involving damage by giant armadillos (Priodontes maximus) to apiaries in the Brazilian Cerrado biome of Mato Grosso do Sul state. From August to November 2018, we interviewed 111 beekeepers identified through a mixed random and snowball sampling design to assess at which level of conflict this interaction could be framed, and to identify strategies able to promote coexistence. Analysis of the five key areas of the framework suggested the current human-wildlife interaction is a level one conflict. This means the negative relation between beekeepers and giant armadillos is still not rooted in less visible, more complex social disagreements, but founded in a material dispute: destruction of beehives. We used the findings to create an intervention strategy which involves: (i) the implementation of mitigation strategies that prevent giant armadillos from predating beehives; (ii) a certification scheme to acknowledge beekeepers' efforts to implement the mitigation strategies, and (iii) a Citizen Science Program using an app that enables data gathering for adaptive management, as well as maintains beekeeper engagement. We hope beekeepers-giant armadillos' coexistence will become beneficial rather than a challenge with the novel interventions.

Keywords: beekeeping, coexistence, conflict analysis, human-wildlife conflicts, wildlife damage management

\section{INTRODUCTION}

Damage caused by wildlife is one of the reasons preventing the peaceful coexistence between humans and wildlife (Kansky et al., 2014), because it may lead to material and economic losses, threaten livelihoods (Messmer, 2009), and even impact the mental health of the people involved (Thondhlana et al., 2020). Retaliatory killing of animals blamed for damage may follow (Cerri et al., 2017), which translates into a worldwide threat to numerous species (Woodroffe et al., 2005). 
Due to that, conservationists and wildlife managers have searched means to manage such challenges. One approach is to directly tackle negative impacts caused by wildlife, with two main strategies commonly adopted in those situations. The first is damage mitigation which seeks either to influence the behavior of the damaging animal (e.g., deterrents for crop-raiding elephants; King et al., 2011), or to reduce the vulnerability of the target (e.g., preventive husbandry; Dickman et al., 2018). The second approach relies on economic instruments to offset impacts, such as insurance (Chen et al., 2013) and financial compensation for the losses incurred (Bauer et al., 2017).

Yet, measures to reduce damage or to provide financial benefits may not necessarily lead to the desired or hoped for peaceful coexistence (Naughton-Treves et al., 2003). Previous evidence indicates the levels of wildlife damage or losses experienced are not always directly related to retaliation or to resentment levels (Dickman, 2010; Marchini and Macdonald, 2012; Kansky et al., 2016). Other factors may impair coexistence, including non-tangible characteristics of a person (e.g., empathy for the species), society (e.g., social identity), culture or institution (see Pooley et al., 2017; Thondhlana et al., 2020). For example, Cavalcanti et al. (2010) found that human persecution to jaguars in Brazil was better explained by a cultural status associated with jaguar hunting than by the economic impacts of their livestock depredation. Neglecting these less visible and non-tangible elements may constrain conflict identification and hinder appropriate solutions, therefore leading to ineffective interventions (Dayer et al., 2019), or even raising negative perceptions of the species leading to escalating human retaliatory practices (Madden, 2004).

To overcome the limitations of current conservation approaches to conflicts, at least two studies have argued for the importance of incorporating the principles and processes of both conflict analysis and peacebuilding research fields. Madden and Mcquinn (2014) claim the knowledge from these fields may provide tools to qualify the challenges of human-wildlife conflicts and coexistence, as well as can guide more effective interventions. The authors propose an analytical model that classifies three levels of conflict. The first is when material and financial losses are at the core of the problem; therefore, preventing or compensating these losses suffices to alleviate such conflicts. The second level is when the people affected by damage may hold strong resentment toward the responsible species, or to other stakeholders addressing the issue (e.g., conservationists). Interventions at this level are less straightforward and may require strengthening relationships between stakeholders involved. Finally, the third level is when a deep-rooted conflict is at play, involving antagonistic values, beliefs or identities. In this case, interventions require complex approaches to reconcile divergent perceptions.

Based on Madden and Mcquinn (2014), Zimmerman et al. (2020) advance on practical guidance on how to identify the conflict level of a given negative interaction between humans and wildlife. The authors suggest investigating five key areas: (i) perception of the species blamed; (ii) exploration of previous attempts to solve the situation; (iii) questions about the situation itself; (iv) the extent of people's willingness to find solutions, and (v) views about others involved in the context or trying to assist with solutions.

Despite the proposed framework relevance to human-wildlife interactions, to our knowledge, the structure of investigation described by Zimmerman et al. (2020) has not been groundtested in a problematic human-wildlife coexistence situation. Therefore, in this article, we advance from this study and the current conservation literature in two ways. First, we extend the proposed framework by suggesting how to assess the five key areas of investigation using qualitative and quantitative social research methods. Second, we apply the framework to investigate whether damage by giant armadillos (Priodontes maximus) to apiaries in the Brazilian Cerrado biome can be characterized as conflict and, if so, at what level. Understanding interactions between beekeepers and giant armadillos may allow practitioners in the conservation field to design more effective interventions to help promote a peaceful coexistence between humans and wildlife.

\section{METHODS}

\section{The Human-Giant Armadillo Interactions and Study Site}

The study was conducted in the giant armadillo's distribution within the Cerrado biome of Mato Grosso do Sul (MS) state of Brazil (Figure 1) (Ferraz et al., 2021), where honey production is an important activity. The state has the highest production per hive/year in Brazil, $34 \mathrm{~kg}$ above the $18 \mathrm{~kg}$ national average (FEAMS - Federação de Apicultura e Meliponicultura do Mato Grosso do Sul, 2017). Beekeeping has also been steadily increasing in family agricultural practices worldwide, due to its potential inclusiveness amongst smallholders (Gonçalves, 2006).

In the Cerrado biome of MS, beekeepers place hives along the edges of native vegetation remnants to allow wildflowers' visitation by bees. Brazil's Cerrado is a highly diverse savanna ecosystem, which provides critical habitat for several endemic and rare species (Klink and Machado, 2005). Yet more than half of the original Brazilian Cerrado has been transformed into pasture or cash crop agriculture, whereas only $19.8 \%$ remains undisturbed (Green et al., 2019). In MS, there are 58,459 $\mathrm{km}^{2}$ of remaining Cerrado left, which is $16 \%$ of the total state area (Reynolds et al., 2016). The remaining MS Cerrado is highly fragmented and predominantly found in small patches (Reynolds et al., 2016), where giant armadillos still survive (Ferraz et al., 2021).

Giant armadillos are the largest living species of their kind, with adults weighing up to $60 \mathrm{~kg}$ and measuring up to $1.5 \mathrm{~m}$ long (Carter et al., 2016; Desbiez et al., 2019). Despite their large size, giant armadillos go frequently unnoticed due to their solitary, nocturnal, and fossorial habitats (Eisenberg and Redford, 1992; Desbiez et al., 2020a). The species feed mainly on ants and termites (Anacleto and Marinho-Filho, 2001), but may opportunistically consume bee larvae (De Melo and Nogueira, 2020). Giant armadillos have learned how to knock over beehives in apiaries to feed (Desbiez et al., 2020b), often imposing substantial economic losses to beekeepers. To overcome this 


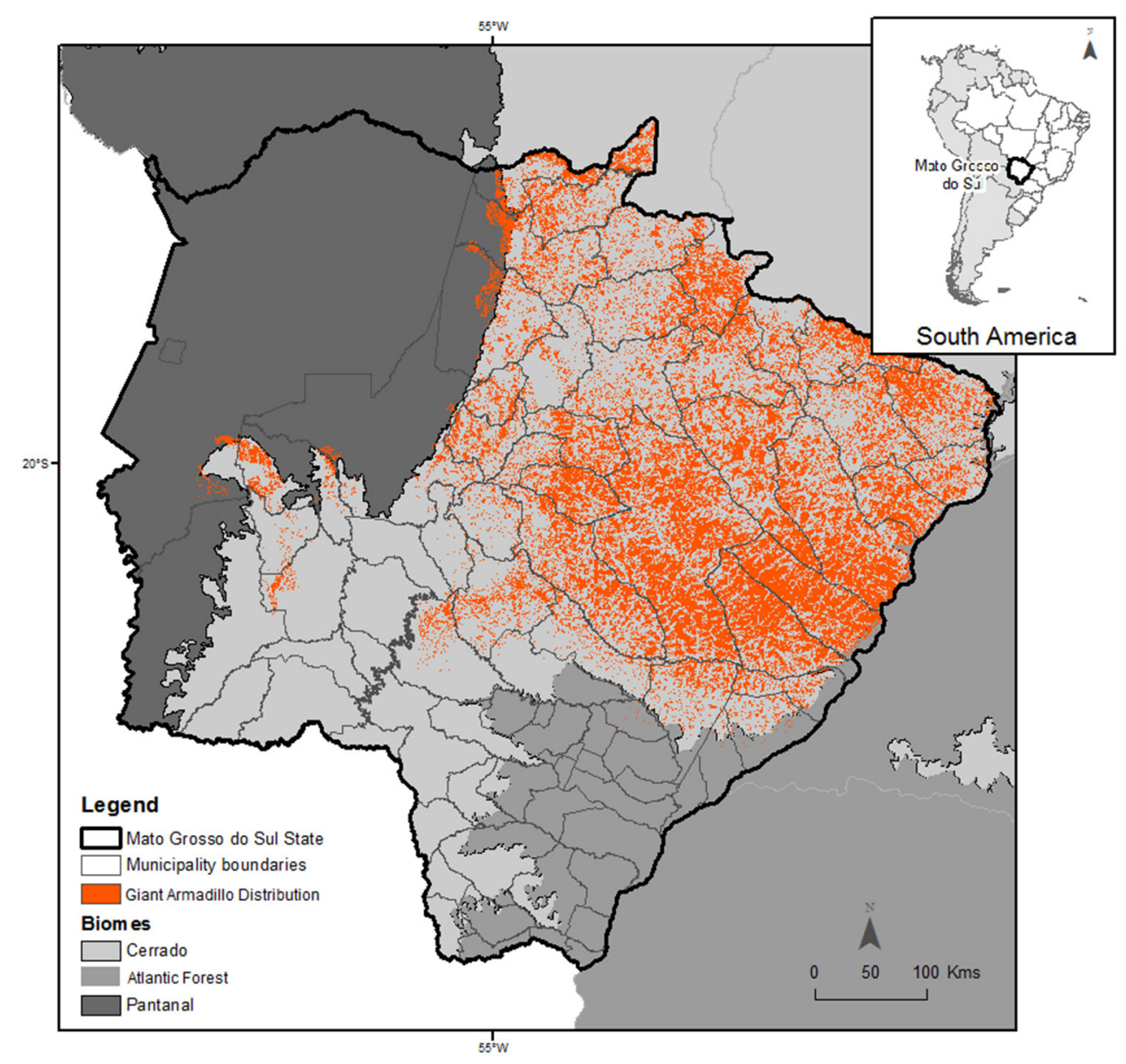

FIGURE 1 | Giant armadillo (Priodontes maximus) distribution in the Cerrado biome of Mato Grosso do Sul state, Brazil (Ferraz et al., 2021).

problem, some beekeepers implement non-lethal strategies such as raising hives or electric fences (for details, see Desbiez et al., 2020b) while others use lethal methods, such as poison. Indeed, giant armadillos are highly susceptible to poisoning because, after destroying beehives, they return to feed on them for several nights. Given giant armadillos' low population densities and low population growth rates (Desbiez et al., 2020a), besides their national/global "Vulnerable" IUCN classification (Anacleto et al., 2014), the loss of a single animal to poisoning can precipitate local extinctions (Desbiez et al., 2020b).

\section{Data Gathering}

To investigate the human-wildlife interaction, our first step was to identify the beekeepers living in giant armadillos' area of occurrence within the Cerrado of Mato Grosso do Sul state. Due to the large dimension of this area, we relied on registration lists of honey producers kept by their association. Using these lists, we randomly selected one beekeeper per municipality $(n=19)$ to be interviewed. However, not all beekeepers were enrolled in the associations, even when they employed equivalent honey management practices. Therefore, this procedure could bias our sample. To avoid biases we combined the random sample from these lists with identification through non-random snowball sampling (Goodman, 1961). Snowballing is an appropriate method when dealing with subjects difficult to access (Newing, 2011), as was the case with non-associated beekeepers. To do that, associated interviewees were asked to name another beekeeper, who then provided another name and so on.

Using a semi-structured interview guide, which was previously pilot- tested (April 2018), we carried out face-to-face interviews with 111 beekeepers from August to November 2018. Information gathered included: sociodemographic information (sex, age, schooling, origin), income sources, beekeeping characteristics (e.g., involvement period; associated or not), and aspects related to the coexistence with giant armadillos. To characterize and better understand the challenges beekeepers face by producing honey alongside giant armadillos, we followed the guidelines in the Zimmerman et al. (2020) framework, thus incorporating the five key areas of analyses. Because the framework did not specify how key areas should be assessed, we devised indicators and associated measures for each of them using quantitative and qualitative social research 
TABLE 1 | Indicators devised to assess each of the five key areas of conflict analysis proposed by Zimmerman et al. (2020), data gathering and analyses.

\begin{tabular}{|c|c|c|c|}
\hline $\begin{array}{l}\text { Key areas of } \\
\text { conflict analysis }\end{array}$ & Indicators used & Data gathering & Data analyses \\
\hline \multirow[t]{5}{*}{$\begin{array}{l}\text { 1. Perception of the } \\
\text { species }\end{array}$} & $\begin{array}{l}\text { i. Beekeepers' views about giant } \\
\text { armadillos }\end{array}$ & Free listing of views about giant armadillos ( 3 words) & $\begin{array}{l}\text { Smith's salience (combination of orde } \\
\text { and frequency of citation) } \\
\text { Word cloud analysis }\end{array}$ \\
\hline & $\begin{array}{l}\text { ii. Perceived benefit of giant } \\
\text { armadillo's existence }\end{array}$ & $\begin{array}{l}\text { Open question: Are there any benefits about giant } \\
\text { armadillo's existence? } \\
\text { Probes for positive answers: What is } \\
\text { (are) such benefit (s)? }\end{array}$ & $\begin{array}{l}\text { Inductive content analysis and } \\
\text { frequency of response's categories }\end{array}$ \\
\hline & $\begin{array}{l}\text { iii. Attitudes toward giant } \\
\text { armadillos }\end{array}$ & $\begin{array}{l}\text { Likert scale composed of six statements } \\
\text { Five points response scale (i.e., from totally agree to } \\
\text { totally disagree) }\end{array}$ & Scale reliability (Cronbach alpha) \\
\hline & $\begin{array}{l}\text { iv. Not in my back yard } \\
\text { sentiment }\end{array}$ & $\begin{array}{l}\text { Closed question: Which destination do you prefer for the } \\
\text { giant armadillo in the future? (five response } \\
\text { categories) }\end{array}$ & Frequency of response categories \\
\hline & $\begin{array}{l}\text { v. Understanding for } \\
\text { the needs of giant armadillos }\end{array}$ & $\begin{array}{l}\text { Open question: Why do you think giant armadillos } \\
\text { destroy the hives? }\end{array}$ & $\begin{array}{l}\text { Inductive content analysis and } \\
\text { frequency of response categories }\end{array}$ \\
\hline \multirow[t]{6}{*}{$\begin{array}{l}\text { 2. Conflict situation } \\
\text { itself }\end{array}$} & i. Limitations to beekeeping & $\begin{array}{l}\text { Open question: What are the main current and past ( } 5 \\
\text { year ago) limitations to beekeeping? }\end{array}$ & $\begin{array}{l}\text { Inductive content analysis and } \\
\text { frequency of response categories }\end{array}$ \\
\hline & $\begin{array}{l}\text { ii. The severity of giant armadillo } \\
\text { damage to beehives }\end{array}$ & $\begin{array}{l}\text { Absolute number (last } 12 \text { months and } 5 \text { years ago) } \\
\text { Percentage of the total production } \\
\text { (last } 12 \text { months) }\end{array}$ & Descriptive analyses \\
\hline & $\begin{array}{l}\text { iii. Attitudes toward giant } \\
\text { armadillo persecution }\end{array}$ & $\begin{array}{l}\text { Likert scale composed of six statements (using target, } \\
\text { action, context and time- specific). } \\
\text { Five points response scale (i.e., from } \\
\text { totally agree to totally disagree) }\end{array}$ & Scale reliability (Cronbach alpha) \\
\hline & $\begin{array}{l}\text { iv. Relationship between } \\
\text { damage and attitudes toward } \\
\text { giant armadillos }\end{array}$ & $\begin{array}{l}\text { Damage: number of beehives destroyed in the last } 12 \\
\text { months Attitudes: Likert scale composed of six } \\
\text { statements }\end{array}$ & $\begin{array}{l}\text { Kruskal-Wallis test plus Bonferroni } \\
\text { post-hoc } \\
\text { Multinomial logistic regression }\end{array}$ \\
\hline & $\begin{array}{l}\text { v. Relationship between } \\
\text { damage and attitudes toward } \\
\text { giant armadillos' } \\
\text { persecution }\end{array}$ & $\begin{array}{l}\text { Damage: number of beehives destroyed in the last } 12 \\
\text { months Attitudes: Likert scale composed of six } \\
\text { statements }\end{array}$ & $\begin{array}{l}\text { Kruskal-Wallis test plus Bonferroni } \\
\text { post-hoc } \\
\text { Multinomial logistic regression }\end{array}$ \\
\hline & $\begin{array}{l}\text { vi. Beekeepers' tolerance to } \\
\text { damage by giant } \\
\text { armadillos }\end{array}$ & $\begin{array}{l}\text { The proportion of individuals who have positive attitudes } \\
\text { toward a species despite suffering damages from the } \\
\text { same species }\end{array}$ & Tolerance to damage index \\
\hline $\begin{array}{l}\text { 3. History of attempts } \\
\text { to solve the conflict }\end{array}$ & $\begin{array}{l}\text { i. Beekeepers' strategies to } \\
\text { prevent damage by giant } \\
\text { armadillos }\end{array}$ & $\begin{array}{l}\text { Number of beekeepers using non- lethal and lethal } \\
\text { strategies } \\
\text { Strategies ranked in low, medium, and } \\
\text { high effectivity }\end{array}$ & $\begin{array}{l}\text { Coding and frequency of response } \\
\text { categories }\end{array}$ \\
\hline $\begin{array}{l}\text { 4. Willingness to find } \\
\text { solutions }\end{array}$ & $\begin{array}{l}\text { i. Beekeepers' willingness to } \\
\text { adapt management } \\
\text { practices }\end{array}$ & $\begin{array}{l}\text { Closed question: How willing would you be to adapt your } \\
\text { management practices to stop losing hives to giant } \\
\text { armadillos? }\end{array}$ & Frequency of response categories \\
\hline $\begin{array}{l}\text { 5. Others involved in } \\
\text { the issue }\end{array}$ & $\begin{array}{l}\text { i. Interest in receiving assistance } \\
\text { by third parties } \\
\text { ii. Perceived image of third } \\
\text { parties } \\
\text { iii. Other groups'perceptions }\end{array}$ & $\begin{array}{l}\text { Closed question: Would you like to receive any } \\
\text { assistance to alleviate the challenge of working alongside } \\
\text { giant armadillos? } \\
\text { Probes: Can you tell me more about that? and Who do } \\
\text { you think this help } \\
\text { would come from? }\end{array}$ & $\begin{array}{l}\text { Frequency of response categories } \\
\text { Inductive content analysis }\end{array}$ \\
\hline
\end{tabular}

methods, as described further (see Table 1 for a synthesis of data gathering and Supplementary Material 1 for data analyses details).

\section{Extending the Framework: Devising Indicators}

The number of indicators and the extent to which we investigated subjects in each key area reflected the results of our interview pilot-test. When questions proved useless to elicit important information, we dropped them to shorten our interview.
- First key area: beekeepers' perceptions of giant armadillos

Perception is a concept that can mean different things depending on the discipline. We, therefore, adopted five perception indicators to cover the range of conceptualizations in the Human Dimensions' literature. First, beekeepers' views about giant armadillos were investigated through a free listing of the first three words that came to the interviewee's mind when thinking about giant armadillos. The procedure relies on the rationale that words are symbolic representations of concepts, places or 
objects (Carlston, 2013), allowing inferences about the cultural salience of the items in a given domain. Second, the perceived benefit of the species' existence, an aspect recognized as crucial for enhancing wildlife conservation (Bennett et al., 2017). Third, beekeeper's attitudes toward giant armadillos, and therefore their tendency to respond with some degree of favorableness (or not) to the species (Eagly and Chaiken, 1993). In Social Psychology, attitudes are considered important to explain how people think, feel and respond to wildlife damage (Decker et al., 2012). Fourth, the so-called Not in My Back Yard (NIMBY) sentiment, which considers people's opposition to the existence of undesirable things/species in their own neighborhood (Dear, 1992). Finally, fifth, beekeepers' understanding of giant armadillos' needs, as a measure of the level of comprehension of the species' needs.

\section{- Second key area: the conflict situation}

This key area requires understanding whether people's complaints arise from tangible impacts and experienced losses. To assess this, we first investigated beekeepers' perceptions of their current limitations to beekeeping. Because respondents tend to interpret a given question in light of previous ones, to avoid biases, we posed this question at the interview beginning and before talking about damage by giant armadillos. Second, we asked about the severity of giant armadillo damage to beehives, to assess the intensity of the problem. Third, we assessed attitudes-i.e., how favorable a person was-toward giant armadillo persecution. This information provides insights on how beekeepers would behave in response to giant armadillos' damages (following the Theory of Planned Behavior (Ajzen, 1985). Fourth, the relationship between damage and attitudes toward giant armadillos and their persecution was questioned, to verify if the damage was an important predictor of attitudes. Fifth, we assessed beekeepers' tolerance to giant armadillo's damage. Tolerance is often associated with attitudes in wildlife management literature to understand HWC (Frank, 2016).

- Third key area: previous attempts to address the conflict

We assessed both beekeepers' lethal and non-lethal strategies to prevent giant armadillos' damages, and also gathered information on their effectiveness.

\section{- Fourth key area: willingness to adapt to alleviate conflict}

We used a single-item measure to obtain a direct evaluation of beekeepers' openness to change management practices to reduce conflict.

\section{- Fifth key area: other people involved in the issue}

To investigate beekeepers' perception of other human groups involved, we assessed their openness to receive assistance from third parties (from I would like very much to I wouldn't like). Because trust in a person or group delivering an intervention predicts people's levels of cooperation (Baynham-Herd et al., 2020), we also gathered information on whom they believe this help should and would or not came from.

To investigate perceptions of other human groups involved (e.g., conflictive or not), we first identified the stakeholders in the beekeeper's narrative, including: (1) government authorities responsible for sanitary and safety inspections of hives; (2) eucalyptus plantation companies and landowners, which allow beekeepers to use their lands; (3) federation and associations of beekeepers, and (4) other wildlife conservation groups. We then conducted unstructured interviews (Newing, 2011) from January 2019 to January 2020 with these groups. The interviews were conversations arranged in advance to talk about the role, knowledge, understanding, and consequences of the negative interactions between giant armadillos and beekeepers.

The most representative government authority in this context is CSEAP-MS- Câmara Setorial Consultiva da Apicultura de Mato Grosso do Sul. A.L.J.D. participated in five meetings with representatives of this agency. The perception of the two silvicultural companies operating in the region was obtained through 10 virtual meetings over a year with responsible employees. Ten beekeeping associations situated across the giant armadillo's range in MS Cerrado were consulted through phone interviews with their representatives. Regarding NGOs activities, although the category was superficially mentioned in a few beekeepers' interviews, no organization was named, and we did not find further evidence about any NGO operating on beekeeping issues in the region.

\section{RESULTS}

\section{Applying the Framework Beekeepers' Characteristics}

Among the 111 interviewees, less than half (43.24\%) were born in the study area, and almost all were male (99.1\%) with an average age of 50.1 years old $( \pm 12.54$; range $=27-89)$. This gender bias reflects the overall gender division of labor in the region for beekeeping. Most women do not participate in beehives' management, although they may be involved in honeyselling and bottling. Interviewed beekeepers had, on average, $7.4 \pm 3.2$ years of schooling, although about a third of them $(32.4 \%)$ studied $<4$ years. Beekeeping was the main source of family income for $41.1 \%$ of the interviewees, who relied on honey for half or more of their income. Most beekeepers (64\%) had over 10 years of experience in this activity, whereas only $7.2 \%$ had $<5$ years. Most beekeepers (60\%) were members of beekeeping associations.

\section{Beekeepers' Perceptions Toward Giant Armadillos}

Beekeepers' views about giant armadillos tended to be neutral, as evidenced by the combination of the frequency and rank order in the free listing (Smith's salience). Neutral aspects (e.g., "big," "strong," "rare," "high") were the items most frequently reported-around three times more than either positive (e.g., "beautiful") or negative (e.g., ugly) aspects (Table 2).

On average, beekeepers had favorable attitudes toward giant armadillos (Table 3), and most beekeepers (82\%) regarded giant armadillos as beneficial, albeit about half of them could not specify why (often they provided vague answers: "must have, every species has"). Among the benefits identified, pest control (i.e., eating social insects) was the most frequently mentioned (16\%), followed by benefits associated with burrowing (i.e., seed 
germination and dispersal, ecosystem engineering, 11\%), and species' intrinsic value (i.e., value irrespective of use/service, 9\%).

The analysis of the "not in my backyard" sentiment (NIMBY; Figure 2) indicated most beekeepers do not believe giant armadillos should be eradicated either globally or locally, though they did wish fewer animals occurred in their neighborhoods. In contrast, some of them stated they would prefer that giant armadillos' population remained stable or even increased in their region.

Finally, when asked about the reasons why giant armadillos destroy hives, $97.3 \%$ of beekeepers replied that the animal does so because it needs feeding. In contrast, very few beekeepers (2.7\%) believed giant armadillos typically have a destructivedriven behavior.

TABLE 2 | Frequency, average rank, and salience of beekeepers' perception about giant armadillos (Priodontes maximus) through free-lists.

\begin{tabular}{lccc}
\hline Category & Frequency (\%) & Average rank & Salience \\
\hline Neutral & 94.2 & 2.54 & 0.447 \\
Positive & 39.8 & 1.71 & 0.298 \\
Negative & 30.1 & 2.03 & 0.193 \\
\hline
\end{tabular}

TABLE 3 | Descriptive statistics of beekeepers' attitudes toward giant armadillos (Priodontes maximus) and toward its persecution.

\begin{tabular}{lccccc}
\hline Variable & Mean \pm SD & Median & Min $^{\mathbf{a}}$ & Max $^{\mathbf{b}}$ \\
\hline Attitudes toward giant armadillos & $3.51 \pm 6.1$ & 4 & $-11(-12)$ & $12(12)$ \\
$\begin{array}{l}\text { Attitudes toward giant armadillos' } \\
\text { persecution }^{c}\end{array}$ & $-5 \pm 4.4$ & -8 & $-12(-12)$ & $8(12)$
\end{tabular}

a Minimum value observed and minimum possible value observed (in parenthesis).

${ }^{b}$ Maximum value observed and maximum possible value observed (in parenthesis).

${ }^{c}$ Negative values indicate unfavorability to persecution; positive values indicate favorability to persecution.

\section{Conflict Situation}

Over a quarter $(27.9 \%)$ of the interviewees cited damage by giant armadillos as a current limitation to beekeeping, second only to pesticide use cited by $39.6 \%$. When enquired about the main limitation to beekeeping in the prior 5 years, almost half (48.6\%) of the respondents stated giant armadillos were their biggest problem then. Despite that, $46 \%$ per cent of respondents reported at least one beehive damage by giant armadillos in the previous 5 years, equivalent to the rate $(44.14 \%)$ reported for the prior 12 months. Thirty-eight percent of interviewees who had experienced damage reported losing $25-50 \%$ of their beehives in the last 12 months, whereas $42 \%$ lost $<25 \%$ and $20 \%$ lost $>50 \%$ of their beehives.

The damage was an important factor explaining beekeepers' attitudes toward giant armadillos. When comparing attitudes toward the species among three groups of beekeepers (no damage, low damage and medium/high damage), results from a Kruskal-Wallis test indicated a difference $\left(\mathrm{X}^{2}=11.981\right.$, d.f. $=2, p<0.001$ ) between the mean ranks of at least one pair of groups. Comparison between three pairs of groups evidenced a consistent difference on attitudes between beekeepers who experienced medium to high damage. Dunn's pairwise tests for the three pairs of groups evidenced a consistent difference $(p<$ 0.001 ) on attitudes between beekeepers who experienced medium to high damage $(H=35.53)$ and those that did not $(H=64.36)$. However, there was no evidence of difference between the other pairs $(p>0.05)$.

The Kruskal-Wallis test also indicated there was an effect of the group on attitudes toward the giant armadillo persecution $\left[\mathrm{X}^{2}=14.997\right.$; d.f. $\left.=2, p<0.001\right]$. Dunn's pairwise test showed that beekeepers groups differed in how much they agreed with the persecution of giant armadillos $(p<0.001)$. Beekeepers who experienced medium/high damage $(\mathrm{H}=81.56)$ differed from those who did not $(\mathrm{H}=48.67)$. The same result was found when comparing the group that experienced low damage $(\mathrm{H}=57.64)$ and the one that experienced medium to high damage. There was

I wish there were less in my region

I wish there was the same amount as there is currently

I wish there were more in my region

I wish they existed, but not in my region

I prefer not to give my opinion

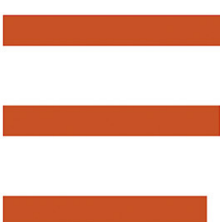

I would like all of them to disappear
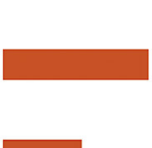

\begin{tabular}{|c|c|c|c|c|}
\hline 0 & 10 & 20 & 30 & 40 \\
\hline
\end{tabular}

FIGURE 2 | Frequency of responses' category to investigate the beekeepers' NIMBY (Not in my back yard) sentiment about giant armadillos (Priodontes maximus). 
no evidence that beekeepers' attitudes differed between those that experienced low damage and those that did not $(p>0.05)$.

The results of the association between damage and attitudes toward giant armadillos (multinomial regressions) display a similar trend. The first multinomial regression tested the importance of damage on beekeepers' attitudes toward giant armadillos (Table 4). Pearson $\left[\mathrm{X}_{(208)}^{2} 199.287, p=0.656\right]$ and Deviance chi-square $\left[\mathrm{X}_{(208)}^{2} 157.454, p=0.996\right]$ tests indicated that this regression model fits the data well and supported the existence of a relationship between the damage extent in the prior 12 months and attitudes toward giant armadillos [Model $\mathrm{X}^{2}$ (d.f. $\left.=12\right)=44.396, p<0.001$; classification accuracy rate $69.4 \%$ higher than the proportional by chance accuracy rate]. Damage was a consistent predictor of attitudes toward the species as beekeepers scoring higher on this variable were more likely to hold negative attitudes toward the species $(b=0.54$, S.E. $=$ $0.016, p<0.001$, odds $=1.055)$. The odds ratio indicates that an increase in damage of 1 beehive destroyed would increase the chance that the beekeeper holds negative attitudes toward giant armadillos by a factor of 1.055. Beekeeping experience (b $=0.051$, S.E. $=0.026, p<0.05$, odds $=1.052)$ and age $(\mathrm{b}=$ 0.49 , S.E. $=0.024, p<0.05$, odds $=1.050$ ) were also significant predictors in the model. Years of formal education, being a member of the beekeeping association and having beekeeping as a main source of income did not correlate with attitudes toward the species.

According to the goodness-of-fit tests (Pearson $\left[\mathrm{X}_{(206)}^{2} 168.337, p=0.974\right]$ and Deviance chi-square $\left[\mathrm{X}_{(206)}^{2} 105.679, p=0.999\right]$ of the second multinomial regression model (Table 4), data supported the effect of damage on attitudes toward giant armadillo persecution [Model $\mathrm{X}^{2}($ d.f. $=12)=$ 45.882, $p<0.001$; classification accuracy rate $71.2 \%$ higher than the proportional by chance accuracy rate]. Extension of damage and social norms -i.e., one's perception about what constitutes appropriate conduct by the own peerscontributed significantly to the model. In contrast, beekeepers' age, beekeeping as the main source of income and beekeeping experience did not contribute to the model. Beekeepers who experienced damage were 1.048 times more likely to be in the favorable to persecution group than in the unfavorable group. Moreover, believing that other beekeepers are favorable and would approve giant armadillos' persecution (i.e., social norms) increased the odds of being in the favorable to persecution group by 5.23 .

Non-negative attitudes toward the species were presented by $65.3 \%$ of beekeepers who experienced damage, showing a Tolerance to Damage Index of 0.09 , indicating high tolerance to giant armadillo damage.

\section{History of Attempts to Prevent Giant Armadillo Predation}

While some beekeepers adopted non-lethal mitigation strategies, others used lethal methods to exterminate hive-damaging animals, including poisoning and trapping. Beekeepers reported that trapping was almost always unsuccessful, time-consuming, and hence frustrating. Poisoning, instead, was considered very successful, as giant armadillos returned
TABLE 4 | Multinomial logistic regressions of the association between beekeepers' characteristics/experience and: (i) attitudes toward giant armadillos (Priodontes maximus) (Model 1) and (ii) attitudes toward their persecution (Model 2).

\begin{tabular}{|c|c|c|c|c|c|}
\hline \multirow[b]{2}{*}{$\begin{array}{l}\text { Response } \\
\text { variable group }\end{array}$} & \multirow[b]{2}{*}{$\begin{array}{l}\text { Predictor variable } \\
\text { Exp }\end{array}$} & \multicolumn{4}{|c|}{$95 \%$ Confidence Interval for $\operatorname{Exp}(B)$} \\
\hline & & (B) & $\boldsymbol{P}$ & $\begin{array}{l}\text { Lower } \\
\text { Limit }\end{array}$ & $\begin{array}{l}\text { Upper } \\
\text { Limit }\end{array}$ \\
\hline
\end{tabular}

Model $1^{\mathrm{a}}$

\begin{tabular}{|c|c|c|c|c|c|}
\hline \multirow{7}{*}{$\begin{array}{l}\text { Negative } \\
\text { attitudes }\end{array}$} & \multicolumn{2}{|l|}{ Intercept } & \multicolumn{3}{|l|}{0.028} \\
\hline & Damage & 1.055 & $0.001^{*}$ & 1.024 & 1.088 \\
\hline & Schooling years & 0.841 & 0.084 & 0.692 & 1.023 \\
\hline & Beekeeping experiene & 1.052 & $0.047^{\star}$ & 1.001 & 1.107 \\
\hline & $\begin{array}{l}\text { Being part of an } \\
\text { association }\end{array}$ & 0.887 & 0.839 & 0.279 & 2.820 \\
\hline & Age & 1.050 & $0.044^{\star}$ & 1.001 & 1.101 \\
\hline & $\begin{array}{l}\text { Beekeeping as the } \\
\text { main source of income }\end{array}$ & 0.573 & 0.623 & 0.062 & 5.274 \\
\hline \multirow{7}{*}{$\begin{array}{l}\text { Neutral } \\
\text { attitudes }\end{array}$} & Intercept & & 0.252 & & \\
\hline & Damage & 0.971 & 0.470 & 0.898 & 1.051 \\
\hline & Schooling years & 0.943 & 0.550 & 0.778 & 1.143 \\
\hline & Beekeeping experience & 1.096 & $0.001^{*}$ & 1.039 & 1.156 \\
\hline & $\begin{array}{l}\text { Being part of an } \\
\text { association }\end{array}$ & 1.049 & 0.944 & 0.275 & 3.996 \\
\hline & Age & 0.989 & 0.671 & 0.939 & 1.042 \\
\hline & $\begin{array}{l}\text { Beekeeping as the } \\
\text { main source of income }\end{array}$ & 2.98 & 0.273 & 2,98E-06 & 2,98E-06 \\
\hline \multicolumn{6}{|l|}{ Model $2^{b}$} \\
\hline \multirow{7}{*}{$\begin{array}{l}\text { Favorable to } \\
\text { persecution }\end{array}$} & Intercept & & 0.052 & & \\
\hline & Damage & 1.048 & $0.035^{\star}$ & 1.003 & 1.096 \\
\hline & Schooling years & 0.987 & 0.933 & 0.725 & 1.343 \\
\hline & Beekeeping experience & 1.100 & $0.033^{*}$ & 1.008 & 1.201 \\
\hline & Age & 1.054 & 0.270 & 0.960 & 1.159 \\
\hline & $\begin{array}{l}\text { Beekeeping as the } \\
\text { main source of income }\end{array}$ & 0.121 & 0.062 & 0.013 & 1.113 \\
\hline & Social norms & 5.232 & $0.003^{\star}$ & 1.780 & 15.380 \\
\hline \multirow{7}{*}{$\begin{array}{l}\text { Neutral to } \\
\text { persecution }\end{array}$} & Intercept & & 0.028 & & \\
\hline & Damage & 1.046 & $0.007^{\star}$ & 1.012 & 1.081 \\
\hline & Schooling years & 1.047 & 0.649 & 0.860 & 1.274 \\
\hline & Beekeeping experience & 0.993 & 0.810 & 0.935 & 1.054 \\
\hline & Age & 1.040 & 0.136 & 0.988 & 1.095 \\
\hline & $\begin{array}{l}\text { Beekeeping as the } \\
\text { main source of income }\end{array}$ & 0.404 & 0.174 & 0.109 & 1.493 \\
\hline & Social norms & 1.274 & 0.402 & 0.723 & 2.244 \\
\hline
\end{tabular}

a Reference category: positive attitudes.

${ }^{b}$ Reference category: unfavorable to persecution.

${ }^{*} P<0.05$.

Pseudo $R^{2}$ (Model 1) $=0.39$.

Pseudo $R^{2}$ (Model 2) $=0.46$.

Log likelihood (Model 1) $=157.454$.

Log likelihood (Model 2) = 105.679.

to feed on the fallen bee combs in the following nights after an attack.

Almost all (94.6\%) beekeepers implemented voluntarily, in the previous 12 months, at least one among 10 non-lethal methods intended to prevent giant armadillo attacks. Three of them were considered highly effective, despite only $30.6 \%$ of beekeepers 
have attempted to implement them, while four were considered moderately effective and three little effective. Less than half of the interviewees (41.4\%) previously tested at least one among the low effective measures which failed to prevent giant armadillo damages to their beehives.

\section{Willingness to Find Solutions}

Almost all beekeepers (96.4\%) were willing or very willing to make changes in how they raise bees so as not to lose more hives to giant armadillos.

\section{Other Parties Involved}

The large majority (82\%) of interviewed beekeepers would like or would like very much to receive third-party assistance to end giant armadillos' predation on hives. We identified four potential stakeholders in beekeepers' narrative: government agencies, beekeeper's associations, silvicultural companies, and NGOs. None of them was negatively viewed by beekeepers, although they were somehow ambivalent about the perceived trustworthiness in receiving support from government agencies. While certain government local agencies instilled more confidence (e.g., SENAR-Serviço Nacional de Aprendizagem Rural and AGRAER-Agência de Desenvolvimento Agrário e Extensão Rural), others were considered suspect. Even so, beekeepers did not deny future collaboration with them to devise conflict solutions. Beekeeping associations, where they exist, are active and respected institutions because beekeepers periodically rely on them for expert advice. These associations are often linked to silvicultural companies, which frequently need to implement environmental compensation activities, such as promoting honey production in planted forests and agroforestry systems. These companies are also positively viewed by beekeepers, as they trained and provided the initial equipment to implement beekeeping to most beekeepers. Few beekeepers mentioned NGOs as either potential supporters or opponents, which aligns with the absence of NGOs working with beekeepers in MS.

Results of interviews with other stakeholder groups were equivalent to beekeepers' perceptions. Thus, there is no evidence of conflicting interests or disagreements among the groups involved. Furthermore, the interviews revealed nobody benefits from the damages, as the following evidence confirms.

A consulting government body (CSEAP-MS) congregates all stakeholders responsible for production, sale and consumption of honey, ranging from sanitary requirements, permitting to strategically plan the growth of honey production. The open interview data indicate few stakeholders were aware of the problem or only considered it a localized problem. After presenting our interview results to the CSEAPMS representatives of (CSEAP-MS), they became strong partners in communicating and supporting solutions (see Supplementary Material 2 for an official letter of support).

Interviews with representatives of beekeeping associations revealed they are aware of that armadillo's damages. Yet, since the problem occurs throughout part of the state (giant armadillo distribution area, Figure 1), it never received consideration. As more interviews were conducted, the associations became strong partners in seeking solutions to reduce giant armadillo's damages (see Desbiez et al., 2020b).

The relationship between beekeepers and silvicultural companies arises from Corporate Social Responsibility practices, which encourages companies to lend their lands so that beekeepers can place their hives. In fact, beekeepers most often place their hives on lands belonging to others. While landowners were never concerned with the issue of giant armadillo predation, eucalyptus companies were. Many areas on their properties have been abandoned by beekeepers due to giant armadillo predation because lethal methods such as trapping or poisoning are forbidden by eucalyptus companies in their own lands. For local NGOs, this issue seems to have been ignored.

\section{DISCUSSION}

Understanding the intricacies and drivers of the negative interaction between people and wildlife is necessary, before deciding or suggesting management practices and strategies. By applying the conflict analysis framework proposed by Zimmerman et al. (2020), we gained a good insight about the current coexistence scenario involving beekeepers and giant armadillos. The framework allowed us to describe the current situation at what Zimmerman et al. (2020) called level one conflict. This means what limits beekeepers and giant armadillos peaceful coexistence is not yet rooted in less visible, more complex and subjective social disagreements between people and groups (Madden and Mcquinn, 2014). Most of the current challenge is shaped by a material dispute: destruction of beehives.

However, our findings also suggest the conflict could escalate to the second level. A close examination of each of the five key areas of analysis indicates resentment toward the damage causing species is beginning. Beekeepers' responses to the NIMBY question, as well as accumulated frustration about previous inneffective measures to prevent damage, are evidences in this regard.

For the first key area-i.e., beekeepers' perceptions toward giant armadillos-we adopted several indicators. Results of the free listing indicated negative terms were less frequently and less saliently associated with giant armadillos. Instead, neutral terms predominated (usually physical attributes), followed by positive aspects. Furthermore, three indicators (i.e., attitudes, perception of species' benefits and understanding of its needs) pointed out that most beekeepers highly value, understand, and appreciate giant armadillos. Although damage associated with wildlife often decreases a species' appreciation (Dickman, 2010), the cost-benefit balance of living with damage-causing wildlife is accounted as influencing people's views about a species (Treves and Bruskotter, 2014). Thus, when beekeepers were asked about giant armadillos without mentioning their potential damages, positive perceptions were more likely. 
However, our last indicator to assess perceptions, the NIMBY sentiment (Dear, 1992; Hamazaki and Tanno, 2002), revealed beekeepers' low preference for spatial proximity with giant armadillos. NIMBY term was coined to characterize residents' motivations to protect their turf from the installation of generally undesirable facilities (e.g., incinerators, jails) (Dear, 1992). The concept assumes people often approve of a certain facility and demand its benefits; even so, they are unwilling to pay the costs of hosting it in their backyards (Hamazaki and Tanno, 2002). While giant armadillos may be positively valued, to beekeepers, hosting them locally is undesirable. The unwanted consequence, i.e., giant armadillos' damage to beehives, can be very destructive, therefore affecting beekeepers' livelihoods (Desbiez et al., 2020b). Strong NIMBY sentiment may reflect some resentment toward the species, and often results in antagonism between those who do not need to host and the "host group" (Dear, 1992); in this case, beekeepers coexisting with giant armadillos. Thus, beekeepers' perceptions that living nearby giant armadillos have negative consequences suggest the situation can potentially escalate to the second level, particularly if group disagreements arise (e.g., between beekeepers and wildlife conservationists).

The second key area of analysis suggests the tangible impacts-i.e., losses inflicted by giant armadillos-are at the core of beekeepers' dissatisfaction, in line with level-1 conflicts. This is evidenced by three of our findings.

1. The damage claimed is very salient (i.e., frequent and very destructive). Most interviewees experienced damage by giant armadillos at least once, occasionally with substantial economic losses. A few were even forced to abandon certain honey production locations, due to the extent of giant armadillos' depredation (Desbiez et al., 2020b). Certain conflicts, when closely analyzed, suggest the negative impacts claimed are not always real, but perceived as such (Dickman and Hazzah, 2016). For instance, Maasai inhabitants in Kenya reported high levels of conflict with lions; despite the actual rates of damage were quite low, with $<5 \%$ of all depredation events attributed to lions (Hazzah et al., 2009). In these human-wildlife scenarios, there are often other factors behind people's dissatisfaction which explain the conflict. In the beekeepers-giant armadillos' case, the negative impact claimed -the destruction of beehives- is real and not attributable to other species.

2. Damage plays an important role in explaining beekeepers' attitudes toward giant armadillos and to their persecution. Beekeepers affected by higher level of losses were more likely to hold negative attitudes toward giant armadillos and more favorable to their persecution. This contrasts with other studies that claim the extent of the damage experienced does not directly correlate with the retaliation intensity or the attitude direction (e.g., Naughton-Treves et al., 2003; Shelley et al., 2011). When damage does not drive stakeholders' attitudes toward species, mitigating damage would not alleviate human retaliation and negative perceptions of a given species. In this case, instead, damage clearly drives stakeholders' attitudes toward giant armadillos.
3. Beekeepers' tolerance to giant armadillo's damage is high, another aspect suggested by Zimmerman et al. (2020) to classify this conflict at the first level. This observation contrasts with the evidence presented in a meta-analysis conducted by Kansky et al. (2014). When investigating the attitudes and tolerance toward four groups of damage-causing mammals (carnivores, ungulates, elephants, primates), the authors found lower values of tolerance for all stakeholders evaluated.

The third and fourth key areas of analysis-i.e., the history of attempts to solve conflictive issues and readiness to find solutions-showed beekeepers' high willingness to adapt management habits to reduce losses, another indicative of a firstlevel conflict. In our study, almost all beekeepers were willing or very willing to change their bee management practices to avoid hive losses to giant armadillos. In fact, most of them had already voluntarily implemented at least one non-lethal method to prevent giant armadillos' raids in the last 12 months, reporting variable rates of success. This finding indicates their high readiness to attempt loss reduction without resorting to harmful methods to giant armadillos.

However, less than a third of the interviewees were satisfied with the effectiveness of the attempts. Moreover, $41.4 \%$ of interviewed beekeepers had previously adopted one or more measures which failed to prevent damages to their beehives. Frustrating attempts can lead to resentment toward the species, and an escalation to level 2 conflict. Frustration can also lead beekeepers to resort to easier to implement lethal strategies, such as poisoning.

The fifth key area of analysis seeks to understand the quality of relationships between other stakeholders involved in the issue. No resentment was identified to any of the third parties, recognized by beekeepers as potential contributors to solving the giant armadillo predation issue. They would, in fact, welcome help from third parties. This is a key area of evaluations in conflict analysis, since mistrust and misunderstandings with third parties can potentially lead to noncompliance and opposition to conservation initiatives (Young et al., 2016; Baynham-Herd, 2020). Interviews with other groups involved corroborated beekeepers' perceptions. All interviewed representatives demonstrated great concern about the issue, once they learned about it, and welcomed the devise of solutions aimed at promoting peaceful coexistence between beekeepers and giant armadillos. This finding also highlights that the challenges of coexistence between giant armadillo and beekeepers arise solely from the negative interactions of the former with the later instead of interactions with other human stakeholders.

Although the conceptual framework adopted here proved very useful to this purpose, there are two points that deserve consideration.

First, the structure of investigation described by the authors is well laid out to investigate the viewpoint of the directly affected group which interacts with wildlife-in our case, beekeepers. The key areas of investigation are clearly and logically focused on exploring this group perceptions. Although the authors highlight the need to evaluate the beliefs of other human groups involved, 
the topic is not further explored, giving a false impression that this aspect is secondary.

Second, it has been previously argued, in the conservation literature, that if a given human-wildlife interaction is only framed by negative impacts between wildlife and people, it does not constitute a conflict. Thus, perhaps labeling it as level one conflict may be inappropriate.

\section{Conservation Implications}

Dealing with challenges arising from human-wildlife coexistence requires adapting approaches according to the strength, characteristics and drivers of a given situation. The framework proposed by Zimmerman et al. (2020), and extended with our methods' detailing, allowed us to evaluate beekeepersgiant armadillos' interaction as predominantly shaped by the economic loss of beehives. The main implication of this is that technical solutions aimed at preventing damage and economic losses and/or by providing financial benefits to people negatively affected by wildlife may successfully promote harmonious coexistence. These findings allowed us to devise three conflict mitigation strategies, together with beekeepers, which are more appropriate to reduce hives' predation and thus human-wildlife negative interactions.

Our first strategy was to compile information learned from this study and from field trials on the efficiency of different measures that may prevent giant armadillo's damages to beehives into a guide which explains how beekeepers can coexist with giant armadillos (see https://www.canastrasecolmeias.org.br/guias-emanuais and Desbiez et al., 2020b).

Yet interventions which increase knowledge are poor proxies for behavioral changes (Kollmuss and Agyeman, 2002) unless people are motivated to do so (they have an interest in changing) and have the capacity to change (Veríssimo et al., 2019). Our results indicate a high percentage of beekeepers are willing to change, whereas less than a third of them were satisfied with current mitigation practices. By evaluating this aspect in the framework, we became aware of the need to transfer knowledge about more efficient methods. To further enhance our impact, we also have hired a beekeeper to act as an extensionist who supports and guide other beekeepers.

However, as said, interventions such as mitigation strategies are effective only when people are able to change, i.e., to implement them (Veríssimo et al., 2019), but beekeepers' do incur on extra time and financial burden to do so (Desbiez et al., 2020b). Thus, there is a concern that even those more motivated may be unable to implement mitigation strategies. As yet we believe this would not be a problem.

One measure often adopted to mitigate the economic burden of more environmentally-friendly production strategies is certification. Certification of wildlife-friendly products has been frequently implemented to promote human-wildlife coexistence (Bogezi et al., 2019). Based on these previous experiences, we have implemented, as a second strategy, a certification process, labeled Giant Armadillo Friendly Honey, which should compensate the extra beekeepers' effort through increased access environmentally-aware niche markets and adding value to their products. There are no financial or administrative costs to enroll in the certification system. By signing a contract, beekeepers must agree to a set of norms, which include best practices and the use of efficient mitigation measures to prevent giant armadillo's predation. The certification system has been approved and is supported by CSEAP-MS, responsible for norm enforcement during inspections. A pilot study was conducted to test the certification implementation and to gather feedback from participant beekeepers. As of May 2021, certification is open to any beekeeper in the ecological range of giant armadillos in this MS state. In the future, the idea is to expand the initiative to the rest of the Cerrado and then, perhaps throughout the species' range.

Our last ongoing measure is to create a smartphone application (app) in which beekeepers can register all events related to giant armadillos, such as beehive's attacks. The app will also serve to keep regular communication with beekeepers about mitigation strategies, the species and market aspects for armadillo's friendly honey. This strategy has two potential positive outcomes. Data registered through this approach can contribute to improve mitigation strategies, besides raising beekeepers' awareness. Moreover, the app will likely increase communication with beekeepers and, in doing so, sustain their regular and long-term involvement in providing quick feedback to implemented interventions.

We expect all these approaches will lead, in the long-term, to retaliation eradication. Coexistence between people and wildlife, even when levels of tolerance are high, can quickly deteriorate (Gureja, 2007). Through the giant armadillo friendly certification process, continued engagement with beekeepers, we expect not only to eradicate both beehives' predation and lethal retaliation, but also to turn beekeepers into allies of giant armadillos' conservation because they are regarded as beneficial rather than a nuisance.

\section{DATA AVAILABILITY STATEMENT}

The raw data supporting the conclusions of this article will be made available by the authors, without undue reservation.

\section{ETHICS STATEMENT}

The studies involving human participants were reviewed and approved by Brazilian National Commission for Research Ethics (CAAE $\mathrm{n}^{\circ}$ 34264820.1.0000.516). The participants provided their written informed consent to participate in this study.

\section{AUTHOR CONTRIBUTIONS}

This study was part of MLC Ph.D. thesis who helped design the study and interviews, analyzed the data, and wrote the previous and current version of the document. CM supervised the data analysis, revised the interview protocol, as well as earlier and 
current versions of the article. BO conducted interviews and tabulated data. ALJD coordinates the Giant Armadillo's Project, coordinated and participated in part of the interviews, devised and implemented conservation measures, and revised the current version of the article. All authors contributed to the article and approved the submitted version.

\section{FUNDING}

MLC was financed by a Ph.D. studentship from Coordenação de Aperfeiçoamento de Pessoal de Nível Superior-Brazil (CAPES)-Finance Code 001. ICAS financed the fieldwork through funds for ongoing project provided by The Whitley Fund for Nature, Disney Conservation fund, Houston Zoo, The Boticário Foundation, and the Zoological and Botanical Garden Wilhelma in Stuttgart.

\section{REFERENCES}

Ajzen, I. (1985). From Intentions to Actions: A Theory of Planned Behavior. Berlin: Springer.

Anacleto, T. C. S., and Marinho-Filho, J. (2001). Hábito alimentar do tatu-canastra (Xenarthra, Dasypodidae) em uma área de cerrado do Brasil Central. Rev. Brasil. Zool. 18, 681-688 doi: 10.1590/S0101-81752001000300003

Anacleto, T. C. S., Miranda, F., Medri, I., Cuéllar, E., Abba, A. M., and Superina, M. (2014). Priodontes maximus. International Union for Conservation and Nature, Red List of Threatened Species. 2014:e.T18144A47442343. doi: 10.2305/IUCN.UK.2014-1.RLTS.T18144A47442343.en

Bauer, H., Muller, L., Van Der Goes, D., and Sillero-Zubiri, C. (2017). Financial compensation for damage to livestock by lions Panthera leo on community rangelands in Kenya. Oryx 51, 106-114. doi: 10.1017/S003060531500068X

Baynham-Herd, Z., Bunnefeld, N., Molony, T., Redpath, S., and Keane, A. (2020). Intervener trustworthiness predicts cooperation with conservation interventions in an elephant conflict public goods game. People Nat. 2, 10751084. doi: 10.1002/pan3.10134

Baynham-Herd, Z. M. D. (2020). Behavioral interventions in conservation conflicts. [dissertation thesis], University of Edinburgh, Edinburgh.

Bennett, N. J., Roth, R., Klain, S. C., Christie, P., Clark, D. A., Cullman, G., et al. (2017). Conservation social science: understanding and integrating human dimensions to improve conservation. Biol. Conserv. 205, 93-108. doi: 10.1016/j.biocon.2016.10.006

Bogezi, C., van Eeden, L. M., Wirsing, A., and Marzluff, J. (2019). Predator-friendly beef certification as an economic strategy to promote coexistence between ranchers and wolves. Front. Ecol. Evolut. 7:476. doi: 10.3389/fevo.2019.00476

Carlston, D. E. (2013). The Oxford Handbook of Social Cognition. Oxford: Oxford University Press. doi: 10.1093/oxfordhb/9780199730018.001.0001

Carter, T. S., Superina, M., and Leslie, D. M. (2016). Priodontes maximus (Cingulata: Chlamyphoridae). Mammalian Species 48:932. doi: $10.1093 / \mathrm{mspecies} /$ sew002

Cavalcanti, S., Marchini, S., Zimmerman, A., Gese, E. M., and Macdonald, D. W. (2010). "Jaguars, livestock, and people in Brazil: realities and perceptions behind the conflict," in The Biology and Conservation of Wild Felids, eds D. Macdonald and A. Loveridge (Oxford: Oxford University Press), 383-402.

Cerri, J., Mori, E., Vivarelli, M., and Zaccaroni, M. (2017). Are wildlife value orientations useful tools to explain tolerance and illegal killing of wildlife by farmers in response to crop damage? Eur. J. Wildl. Res. 63:70. doi: 10.1007/s10344-017-1127-0

Chen, S.,Yi, Z., Campos-arceiz, A., Chen, M., and Webb, E. (2013). Developing a spatially-explicit, sustainable and risk-based insurance scheme to mitigate human-wildlife conflict. Biol. Conserv. 168, 31-39. doi: 10.1016/j.biocon.2013.09.017

\section{ACKNOWLEDGMENTS}

We are grateful to representatives of beekeepers' associations in Mato Grosso do Sul state for their help in providing us the contacts of associates, and to all beekeepers who patiently participated in the interviews. We also thank Alexandra Zimmermann for coming to the field, helping with the interview design and encouraging us.

\section{SUPPLEMENTARY MATERIAL}

The Supplementary Material for this article can be found online at: https://www.frontiersin.org/articles/10.3389/fcosc. 2021.696435/full\#supplementary-material

Supplementary Material 1 | Analyses details.

Supplementary Material $2 \mid$ Official letter of support.

Dayer, A. A., Willians, A., Cosbar, E., and Racey, M. (2019). Blaming threatened species: media portrayal of human-wildlife conflict. Oryx 53:2. doi: $10.1017 /$ S0030605317000783

De Melo, A. T. N., and Nogueira, B. D. S. (2020). Field Note. Giant armadillo (Priodontes maximus Kerr, 1792; Cingulata: Chlamyphoridae) attacks nest of stingless bee Trigona amalthea (Olivier, 1789) (Hymenoptera: Apidae). Edentata 21, 38-41. doi: 10.2305/IUCN.CH.2020.Edentata-20-1.6.en

Dear, M. (1992). Understanding and overcoming the NIMBY syndrome. J. Am. Plann. Assoc. 58, 288-300. doi: 10.1080/01944369208975808

Decker, D. J., Riley, S. J., and Siemer, W. F. (2012). Human Dimensions of Wildlife Management. Baltimore: JHU Press.

Desbiez, A. L. J., Kluyber, D., Massocato, G. F., Oliveira-Santos, L. G. R., and Attias, N. (2020a). Spatial ecology of the giant armadillo Priodontes maximus in Midwestern Brazil. J. Mammal. 101, 151-163. doi: 10.1093/jmammal/gyz172

Desbiez, A. L. J., Massocato, G. F., Kluyber, D., Luba, C. N., and Attias, N. (2019). How giant are giant armadillos? The morphometry of giant armadillos (Priodontes maximus Kerr, 1792) in the Pantanal of Brazil. Mammalian Biol. 95, 9-14. doi: 10.1016/j.mambio.2018.12.007

Desbiez, A. L. J., Oliveira, B., and Catapani, M. L. (2020b). Bee careful! Conflict between beekeepers and giant armadillos (Priodontes maximus) and potential ways to coexist. Edentata 21, 1-12. doi: 10.2305/IUCN.CH.2020

Dickman, A., Potgieter, G., Horgan, J., Stoner, K., Klein, R., and McManus, J. (2018). "Use of livestock guarding dogs to reduce human-cheetah conflict," in Biodiversity of the World - Cheetahs: Biology and Conservation (San Diego, CA: Elsevier; Academic Press), 209-221. doi: 10.1016/B978-0-12-804088-1.0 0015-0

Dickman, A. J. (2010). Complexities of conflict: the importance of considering social factors for effectively resolving human-wildlife conflict. Anim. Conserv. 13, 458-466. doi: 10.1111/j.1469-1795.2010.0 0368.x

Dickman, A. J., and Hazzah, L. (2016). "Money, myths and man-eaters: complexities of human-wildlife conflict," in Problematic Wildlife, ed. F. M. Angelici (Cham: Springer), 339-356.

Eagly, A. H., and Chaiken, S. (1993). The Psychology of Attitudes. New York, NY: Harcourt Brace Jovanovich College Publishers.

Eisenberg, J. F., and Redford, K. H. (1992). Mammals of the Neotropics. The Southern Cone: Chile, Argentina, Uruguay, Paraguay. Chicago, IL: University of Chicago Press.

FEAMS - Federação de Apicultura e Meliponicultura do Mato Grosso do Sul (2017). Revista Mensagem Doce 144.

Ferraz, K. M. P. M. B., de Oliveira, B. G., Attias, N., and Jean Desbie, A. L. (2021). Species distribution model reveals only highly fragmented suitable patches remaining for giant armadillo in the Brazilian Cerrado. Perspect. Ecol. Conserv. 19, 43-52. doi: 10.1016/j.pecon.2021.01.001 
Frank, B. (2016). Human-wildlife conflicts and the need to include tolerance and coexistence: an introductory comment. Soc. Nat. Resour. 29, 738-743. doi: 10.1080/08941920.2015.1103388

Gonçalves, L. S. (2006). Desenvolvimento e expansão da apicultura no Brasil com abelhas africanizadas. Rev. Sebrae 3, 14-16.

Goodman, L. A. (1961). Snowball sampling. Ann. Math. Statist. 32, 148-170. doi: $10.1214 /$ aoms/1177705148

Green, J. M. H., Croft, S. A., Durán, A. P., Balmford, A. P., Bugess, N. D., Fick, S., et al. (2019). Linking global drivers of agricultural trade to on-theground impacts on biodiversity. Proc. Nat. Acad. Sci. U.S.A. 116, 23202-23208. doi: 10.1073/pnas.1905618116

Gureja, N. (2007). Ganesha to Bin Laden: Human-Elephant Conflict in Sonitpur District of Assam. Wildlife Trust of India. Occasional Report n. 06. Wildlife Trust of India, 2007.

Hamazaki, T., and Tanno, D. (2002). Totemization of wildlife and NIMBYamong US College Students. Human Dimens Wildlife 7, 107-121. doi: 10.1080/10871200290089373

Hazzah, L., Mulder, M. B., and Frank, L. G. (2009). Lions and warriors: social factors underlying declining African lion populations and the effect of incentive-based management in Kenya. Biol. Conserv. 142, 2428-2437. doi: 10.1016/j.biocon.2009.06.006

Kansky, R., Kidd, M., and Knight, A. T. (2014). Meta-analysis of attitudes toward damage-causing mammalian wildlife. Conserv. Biol. 28, 924-938. doi: $10.1111 /$ cobi. 12275

Kansky, R., Kidd, M., and Knight, A. T. (2016). A wildlife tolerance model and case study for understanding human wildlife conflicts. Biol. Conserv. 201, 137-145. doi: 10.1016/j.biocon.2016.07.002

King, L. E., Douglas-Hamilton, I., and Vollrath, F. (2011). Beehive fences as effective deterrents for crop-raiding elephants: field trials in northern Kenya. Afr. J. Ecol. 49, 431-439. doi: 10.1111/j.1365-2028.2011.01275.x

Klink, C. A., and Machado, R. B. (2005). Conservation of the Brazilian Cerrado. Conserv. Biol. 19, 707-713. doi: 10.1111/j.1523-1739.2005.00702.x

Kollmuss, A., and Agyeman, J. (2002). Mind the gap: why do people act environmentally and what are the barriers to pro-environmental behavior? Environ. Educ. Res. 8, 239-260. doi: 10.1080/13504620220145401

Madden, F. (2004). Creating coexistence between humans and wildlife: global perspectives on local efforts to address human-wildlife conflict. Human Dimens Wildlife 9, 247-257. doi: 10.1080/10871200490505675

Madden, F., and Mcquinn, B. (2014). Conservation's blind spot: the case for conflict transformation in wildlife conservation. Biol. Conserv. 178, 97-106. doi: 10.1016/j.biocon.2014.07.015

Marchini, S., and Macdonald, D. W. (2012). Predicting ranchers' intention to kill jaguars: case studies in Amazonia and Pantanal. Biol. Conserv. 147, 213-221. doi: 10.1016/j.biocon.2012.01.002

Messmer, T. A. (2009). Human-wildlife conflicts: emerging challenges and opportunities. Human- Wildlife Conflicts 3, 10-17. Available online at: www. jstor.org/stable/24875682

Naughton-Treves, L., Grossberg, R., and Treves, A. (2003). Paying for tolerance: rural citizens' attitudes toward wolf depredation and compensation. Conserv. Biol. 17, 1500-1511. doi: 10.1111/j.1523-1739.2003.00060.x

Newing, H. (2011). Conducting Research in Conservation: Social Science Methods and Practice. New York, NY: Routledge.
Pooley, S., Barua, M., Beinart, W., Dickman, A., Holmes, G., Lorimer, J., et al. (2017). An interdisciplinary review of current and future approaches to improving human-predator relations. Conserv. Biol. 31, 513-523. doi: 10.1111/cobi.12859

Reynolds, J., Wesson, K., Desbiez, A. L. J., Ochoa-Quintero, J. M., and Leimgruber, P. (2016). Using remote sensing and random forest to assess the conservation status of critical Cerrado habitats in Mato Grosso do Sul, Brazil. Land 5:12. doi: 10.3390/land5020012

Shelley, V., Treves, A., and Naughton, L. (2011). Attitudes to wolves and wolf policy among Ojibwe tribal members and non-tribal residents of Wisconsin's wolf range. Human Dimens. Wildlife 16, 397-413. doi: 10.1080/10871209.2011.606521

Thondhlana, G., Redpath, S. M., Vedeld, P. O., van Eden, L., Pascual, U., Sherren, K., et al. (2020). Non-material costs of wildlife conservation to local people and their implications for conservation interventions. Biol. Conserv. 246:108578. doi: 10.1016/j.biocon.2020.108578

Treves, A., and Bruskotter, J. (2014). Tolerance for predatory wildlife. Science 344, 476-477. doi: 10.1126/science. 1252690

Veríssimo, D., Tully, B., and Douglas, L. R. (2019). Conservation marketing as a tool to promote human-wildlife coexistence. Human-Wildlife Interact. 1, 335-358. doi: 10.1017/9781108235730.019

Woodroffe, R., Simon, T., and Rabinowitz, A. (2005). People and Wildlife, Conflict or Co-existence? Cambridge: Cambridge University Press.

Young, C., Searle, K., Buttler, A., Simmons, P., Watt, A. D., and Jordan, A. (2016). The role of trust in the resolution of conservation conflicts. Biol. Conserv. 195, 196-202. doi: 10.1016/j.biocon.2015. 12.030

Zimmerman, A., McQuinn, B., and Macdonald, D. W. (2020). Levels of conflict over wildlife: Understanding and addressing the right problem. Conserv. Sci. Practice 2:e259. doi: $10.1111 / \mathrm{csp} 2.259$

Conflict of Interest: The authors declare that the research was conducted in the absence of any commercial or financial relationships that could be construed as a potential conflict of interest.

The handling editor declared a shared affiliation with authors MLC and CM at time of review.

Publisher's Note: All claims expressed in this article are solely those of the authors and do not necessarily represent those of their affiliated organizations, or those of the publisher, the editors and the reviewers. Any product that may be evaluated in this article, or claim that may be made by its manufacturer, is not guaranteed or endorsed by the publisher.

Copyright (ㄷ) 2021 Catapani, Morsello, Oliveira and Desbiez. This is an open-access article distributed under the terms of the Creative Commons Attribution License (CC $B Y)$. The use, distribution or reproduction in other forums is permitted, provided the original author(s) and the copyright owner(s) are credited and that the original publication in this journal is cited, in accordance with accepted academic practice. No use, distribution or reproduction is permitted which does not comply with these terms. 